\title{
Validity of neuron-specific enolase as a prognostic tool in acute ischemic stroke in adults at Suez Canal University Hospital
}

\author{
Mohammed H. Shash ${ }^{1}$, Reda Abdelrazek ${ }^{2 *}$, Nashwa M. Abdelgeleel ${ }^{1}$, Rasha M. Ahmed ${ }^{1}$ and Adel H. El-baih ${ }^{1}$
}

\begin{abstract}
Background: Biological markers of acute nerve cell damage can assist in the outcome of acute ischemic stroke, such as neuron-specific enolase (NSE) that have been tested for association with initial severity of stroke, extent of infarction, and functional outcome.

Objective: To determine short-term prognostic value of the biochemical marker neuron-specific enolase (NSE) in acute ischemic stroke.

Methods: A cohort study carried out on 37 patients with acute ischemic stroke. Data were gathered in a prepared data sheet. Initial serum NSE level was measured to the patients in the Emergency department within $6 \mathrm{~h}$ of the onset of stroke and another measurement after $48 \mathrm{~h}$. National Institute of Health Stroke Scale (NIHSS) was held to the patients at presentation and after 28 days of stroke to determine short-term morbidity and mortality.

Results: Out of the 37 patients, 31 patients survived (no-death group) and 6 patients died (death group). The mean serum level of neuron-specific enolase at presentation and after $48 \mathrm{~h}$ was significantly higher in the death group than in the no-death group. There was a statistically significant positive correlation between neuron-specific enolase (NSE) serum level and clinical severity of stroke (NIHSS) among the patients at presentation $(r=0.737, p=0.000)$.

Conclusion: Neuron-specific enolase (NSE) can be applied as single independent marker for prediction of mortality and short-term morbidity in ischemic stroke patients.
\end{abstract}

Keywords: Ischemic stroke, Neuron-specific enolase (NSE), NIHSS

\section{Introduction}

Stroke is the number one cause of physical disability and the third main cause of death worldwide [1]. The ageadjusted annual stroke death rate is 116 per 100,000 people in the United States and 200 per 100,000 in the United Kingdom, Around $12 \%$ of all deaths. Low- and middle-income countries are significantly more affected than developed countries [2]. Around 17 million persons had a stroke in 2010 and 33 million persons had a stroke before and were still living. Between 1990 and 2010, the

\footnotetext{
*Correspondence: Dr.reda_abdelrazek@yahoo.com

${ }^{2}$ Department of Neurology, Faculty of Medicine, Suez Canal University, Ismailia, Egypt

Full list of author information is available at the end of the article
}

sum of strokes in the developed world decreased by about $10 \%$ and in the developing world increased by $10 \%$ [3]. With an estimated 100 million residents in 2020, Egypt is extremely crowded country in the Middle East. In Egypt, as stated by recent assessment the global prevalence of stroke is high with a rough prevalence of 963/100 000 residents [4].

The $\gamma \gamma$-isoenzyme of the glycolytic enzyme enolase is the neuron-specific enolase (NSE) which is found in peripheral and central nerve cells and neuroendocrine cells, as well as in platelets and erythrocytes. It has been used for assessment of neuroendocrine tumors [5].

NSE is recognized as a neuronal marker in both the mouse and the human brain and only found in trivial 
quantities in the blood. Former research has demonstrated liberation of NSE in the early hours by injured neurons, suggesting functional abnormalities or plasma membrane structural disorder due to ischemia of the brain [6].

Furthermore, NSE has been reported as a neurotrophic factor to promote the persistence of cultured nerve cells in the neocortex of mouse. In the central nervous system, it was known as a "neuronal survival factor" emphasizing the basic relevance of this protein to the metabolism of the nerve cells [7].

Biological markers of acute nerve cell damage can assist in the outcome acute ischemic stroke. Such as neuron-specific enolase (NSE), that have been tested for association with initial severity of stroke, extent of infarction, and functional outcome [8].

\section{Aim}

To determine short-term prognostic value of the biochemical marker neuron-specific enolase (NSE) in an acute ischemic stroke.

\section{Methods}

This study created as a cohort study and carried out in the Emergency Department (ER). Thirty-seven patients of both genders diagnosed as having acute ischemic stroke clinically and by CT or MRI were included. Patients with a previous stroke that affects the assessment of NIHSS, significant heart, liver, kidney, endocrine and malignant disorders, surgical operations, trauma, or acute organ ischemia in the previous 3 months; chronic inflammatory illnesses; fever or acute infections or inflammatory illnesses were excluded [9]. All patients did not receive thrombolytic therapy. The study was approved by the faculty of medicine ethical committee. Written, informed consent was obtained from all subjects before inclusion in the study. The study was conducted from January 2018 to January 2019.

All subjects underwent clinical evaluation containing detailed history, complete general, and neurological examination, basic laboratory investigations and assessing different stroke risk factors as diabetes mellitus, hypertension, atrial fibrillation, smoking and history of previous stroke Assessment of ischemic stroke severity by using the NIHSS score [10] to determine short term morbidity at presentation and after 28 days of stroke for survived patients and before death for the dead patients. Brain neuroimaging using CT scan (Siemens, Balance Somatom, single-slice instrument, Germany) or MRI (1.5 Tesla MR Imager, Achieva, Philips Medical Systems, Best, Netherlands) was carried out for all subjects, The location of infarction (total anterior circulation, partial anterior circulation, lacunar infarction and posterior circulation) was categorized according to the Oxford classification [11].

Assay of serum Neuron Specific Enolase (NSE); Three $\mathrm{ml}$ of venous blood was collected in a red-capped plain vacutainer. Serum was obtained by centrifugation blood

Table 1 Demographic and clinical characteristics of stroke patients $(n=37)$

\begin{tabular}{|c|c|c|c|c|c|}
\hline & Total $(n=37)$ & No-death $(n=31)$ & Death $(n=6)$ & Test of sig. & $p$ \\
\hline \multicolumn{6}{|l|}{ Gender } \\
\hline Male & $25(67.6 \%)$ & $23(74.2 \%)$ & $2(33.3 \%)$ & $x^{2}=3.830$ & $\mathrm{FE}_{p}=0.073$ \\
\hline Female & $12(32.4 \%)$ & $8(25.8 \%)$ & $4(66.7 \%)$ & & \\
\hline \multicolumn{6}{|l|}{ Age (years) } \\
\hline Mean \pm SD & $55.4 \pm 3.0$ & $55.1 \pm 2.8$ & $56.8 \pm 3.9$ & $t=1.271$ & 0.212 \\
\hline Median (Min.-Max.) & $55.0(51.0-61.0)$ & $54.0(51.0-61.0)$ & $58.5(51.0-60.0)$ & & \\
\hline \multicolumn{6}{|l|}{ Risk factors for stroke } \\
\hline Diabetes mellitus & $16(43.2 \%)$ & $12(38.7 \%)$ & $4(66.7 \%)$ & $x^{2}=1.601$ & $\mathrm{FE}_{p}=0.371$ \\
\hline Hypertension & $13(35.1 \%)$ & $10(32.3 \%)$ & $3(50.0 \%)$ & $x^{2}=0.694$ & $\mathrm{FE}_{p}=0.643$ \\
\hline Atrial fibrillation & $17(45.9 \%)$ & 15 (48.4\%) & $2(33.3 \%)$ & $x^{2}=0.459$ & $\mathrm{FE}_{p}=0.667$ \\
\hline Smoking & $20(54.1 \%)$ & $17(54.8 \%)$ & $3(50.0 \%)$ & $x^{2}=0.047$ & $\mathrm{FE}_{p}=1.000$ \\
\hline History of previous stroke & $20(54.1 \%)$ & $16(51.6 \%)$ & $4(66.7 \%)$ & $x^{2}=0.459$ & $\mathrm{FE}_{p}=0.667$ \\
\hline \multicolumn{6}{|l|}{ Oxford classification } \\
\hline Total anterior circulation & $6(16.2 \%)$ & $2(6.5 \%)$ & $4(66.7 \%)$ & $x^{2}=13.416^{*}$ & $\mathrm{FE}_{p}=0.003^{*}$ \\
\hline Partial anterior circulation & $24(64.9 \%)$ & $22(71.0 \%)$ & $2(33.3 \%)$ & $x^{2}=3.124$ & $\mathrm{FE}_{p}=0.157$ \\
\hline Posterior circulation & $7(18.9 \%)$ & $7(22.6 \%)$ & $0(0.0 \%)$ & $x^{2}=1.671$ & $\mathrm{FE}_{p}=0.571$ \\
\hline Lacunar infarction & $0(0 \%)$ & $0(0 \%)$ & $0(0 \%)$ & - & - \\
\hline
\end{tabular}

$X^{2}$, chi-square test; $F E$, Fisher exact; $t$, Student's $t$ test; $p, p$ value for comparing between the two studied groups

* Statistically significant at $p \leq 0.05$ 
Table 2 Relation between age and risk factors for stroke among the patients ( $n=37$ )

\begin{tabular}{|c|c|c|c|c|c|c|}
\hline \multirow[t]{2}{*}{ Risk factors for stroke } & \multirow[t]{2}{*}{$N$} & \multicolumn{3}{|l|}{ Age (years) } & \multirow[t]{2}{*}{$t$} & \multirow[t]{2}{*}{$p$} \\
\hline & & Min.-Max. & Mean \pm SD & Median & & \\
\hline Diabetes mellitus & 16 & $51.0-60.0$ & $55.8 \pm 3$ & 56 & 0.598 & 0.554 \\
\hline Hypertension & 13 & $51.0-60.0$ & $56 \pm 3.2$ & 56 & 0.875 & 0.387 \\
\hline Atrial fibrillation & 17 & $51-61$ & $56 \pm 2.87$ & 56 & 1.103 & 0.277 \\
\hline Smoking & 20 & $51-60$ & $55.3 \pm 3$ & 55 & 0.334 & 0.740 \\
\hline History of previous stroke & 20 & $51-60$ & $55 \pm 3$ & 54 & 0.879 & 0.385 \\
\hline
\end{tabular}

$t$, Student's $t$ test; $p, p$ value for association between different categories

at $1900 \times \mathrm{g}$ at $4{ }^{\circ} \mathrm{C}$ for $15 \mathrm{~min}$. Serum was removed from the clot during $60 \mathrm{~min}$ of collection to bypass leaking of Neuron Specific Enolase from blood cells. Separated serum collected in two aliquots at $-70^{\circ} \mathrm{C}$ till chemical analysis, the serum samples were collected, and NSE serum levels were identified by the CanAg NSE Enzyme Immunometric Assay (EIA) kit (Fujirebio Diagnostics AB. Sweden).The CanAg NSE EIA is a solid-stage, noncompetitive immunoassay built on two monoclonal (mice-derived) antibodies focused against two different NSE molecule antigenic elements. The monoclonal antibodies (MAb) utilized attach to the enzyme's $\gamma$-subunit and thus identify both the form of $\gamma \gamma$ and the form of $\alpha \gamma$. The detection limit of the kit $(1-150 \mu \mathrm{g} / \mathrm{L})$ and normal individuals are anticipated to get NSE values below $13 \mu \mathrm{g} / \mathrm{L}[7-9]$.

Serum NSE level was measured in the patients at Emergency Department at presentation within $6 \mathrm{~h}$ of stroke onset and another measurement after $48 \mathrm{hrs}$.

\section{Statistical analysis}

Data were gathered and then entered as a spread sheet working for windows office 2010, using Microsoft Excel. In the analysis of data using version 20.0 of the IBM SPSS software package, data was fed to the computer and analyzed (Armonk, NY: Published 2016 by IBM Corp). Data were submitted as tables and graphs, opposed to quantitative data stated as mean and standard

Table 3 Distribution of the patients according to timing of death (day) and cause of death

\begin{tabular}{ll}
\hline & No. (\%) \\
\hline Timing of death (days) & \\
Mean \pm SD & $9.2 \pm 3.8$ \\
Median (Min.-Max.) & $8.5(5.0-16.0)$ \\
Cause of death & \\
Brain herniation & $5(83.3 \%)$ \\
Hospital acquired pneumonia & $1(16.7 \%)$ \\
Multiple organ failure & $0(0 \%)$ \\
Use of mechanical ventilation & $0(0 \%)$ \\
\hline
\end{tabular}

deviation using $t$ test and Wilcoxon signed-rank tests. Chi-square (Fisher) and Mann-Whitney tests were applied to compare the number and percentage of the qualitative data presented. ROC-curve was used to evaluate the cutoff point for the marker, the area of more than 50 percent offers adequate performance and the area of the best performance is around 100 percent for the test.

\section{Results}

Out of the 37 patients involved in this study, 31 patients survived and 6 patients died. So, all the study variables were compared in the two groups: no-death group and death group.

The age of the no-death group varied between 51 and 61 years with a mean $(55.1 \pm 2.8)$ and of the death group varied between 51 and 60 years with a mean $(56.8 \pm 3.9)$. Twenty-three subjects $(74.2 \%)$ are males and $8(25.8 \%)$ are females in the no-death group, while in the death group, 2 subjects (33.3\%) are males and 4 subjects (66.7\%) are females. There was no statistically significant difference in age and gender between the two groups (Table 1).

Regarding the different risk factors for strokes in the current study as having diabetes mellitus, hypertension, atrial fibrillation, smoking, and history of previous stroke, no significant difference between death and nodeath groups was observed $(p=0.371,0.643,0.667,1.00$, and 0.667$)$ respectively. For the clinical presentations of the patients, they were classified by Oxford classification which shows more affection of the anterior circulation than the posterior circulation among the patients with the total anterior circulation more significantly affected in the death group than the no-death group $(p=0.003)$ (Table 1). The distribution of the different risk factors for strokes according to the age is shown in Table 2.

The timing of death ranged between 5 and 16 days with a mean $(9.2 \pm 3.8)$. Brain herniation was the main cause of death 5 (83.3\%) followed by hospital-acquired pneumonia 1 (16.7\%) (Table 3).

In the death group at presentation, the mean total NIHSS score was significantly higher $(23.5 \pm 3.1)$ than in the no-death group $(15.1 \pm 3.5)(P<0.001)$. Also, the 
Table 4 Comparison between the serum level of neuron-specific enolase (NSE) and the clinical severity of stroke (NIHSS) among the patients $(n=37)$

\begin{tabular}{|c|c|c|c|c|c|}
\hline & Total $(n=37)$ & No-death $(n=31)$ & Death $(n=6)$ & Test of sig. & $p$ \\
\hline \multicolumn{6}{|l|}{ NSE at presentation } \\
\hline Mean \pm SD & $24.9 \pm 8.8$ & $23.1 \pm 8.1$ & $34.5 \pm 6.2$ & $U=30.50^{*}$ & $0.007^{*}$ \\
\hline Median (Min.-Max.) & $27.8(12.7-42.1)$ & $26.7(12.7-35.3)$ & $36.6(26.8-42.1)$ & & \\
\hline \multicolumn{6}{|l|}{ NSE at $48 \mathrm{~h}$} \\
\hline Mean \pm SD & $24.0 \pm 8.4$ & $22.3 \pm 7.7$ & $33.0 \pm 5.5$ & $U=27.0^{*}$ & $0.005^{*}$ \\
\hline Median (Min.-Max.) & $27.2(11.6-41.0)$ & $24.4(11.6-33.5)$ & $33.2(25.7-41.0)$ & & \\
\hline$z_{p_{1}}$ & $0.002^{*}$ & $0.013^{*}$ & $0.046^{*}$ & & \\
\hline \multicolumn{6}{|l|}{ NIHSS at presentation } \\
\hline Moderate stroke (5-15) & $15(40.5 \%)$ & $15(48.4 \%)$ & $0(0.0 \%)$ & $x^{2}=4.883$ & ${ }^{\mathrm{FE}} p=0.063$ \\
\hline Moderate to severe stroke (16-20) & $17(45.9 \%)$ & $15(48.4 \%)$ & $2(33.3 \%)$ & $x^{2}=0.459$ & ${ }^{\mathrm{FE}} p=0.667$ \\
\hline Severe stroke $\geq 21$ & $5(13.5 \%)$ & $1(3.2 \%)$ & $4(66.7 \%)$ & $x^{2}=17.311^{*}$ & $\mathrm{FE}_{p}=0.001^{*}$ \\
\hline Mean \pm SD & $16.4 \pm 4.6$ & $15.1 \pm 3.5$ & $23.5 \pm 3.1$ & $t=5.517^{*}$ & $<0.001^{*}$ \\
\hline Median (Min.-Max.) & $16.0(10.0-28.0)$ & $16.0(10.0-22.0)$ & $24.0(20.0-28.0)$ & & \\
\hline \multicolumn{6}{|l|}{ NIHSS at 28 days } \\
\hline Moderate stroke (5-15) & $20(54.1 \%)$ & $20(64.5 \%)$ & $0(0.0 \%)$ & $x^{2}=8.425^{*}$ & $\mathrm{FE}_{p}=0.005^{*}$ \\
\hline Moderate to severe stroke (16-20) & $11(29.7 \%)$ & $11(35.5 \%)$ & $0(0.0 \%)$ & $x^{2}=3.030^{*}$ & $\mathrm{FE}_{p}=0.151$ \\
\hline Severe stroke $\geq 21$ & $6(16.2 \%)$ & $0(0.0 \%)$ & $6(100.0 \%)$ & $x^{2}=37.0^{*}$ & ${ }^{\mathrm{FE}} p<0.001^{*}$ \\
\hline Mean \pm SD & $15.6 \pm 5.8$ & $13.7 \pm 3.8$ & $25.7 \pm 3.2$ & $t=7.152^{*}$ & $<0.001^{*}$ \\
\hline Median (Min.-Max.) & $14.0(7.0-30.0)$ & $13.0(7.0-20.0)$ & $26.0(22.0-30.0)$ & & \\
\hline${ }^{t} p_{1}$ & $0.008^{*}$ & $<0.001^{*}$ & $0.003^{*}$ & & \\
\hline
\end{tabular}

$X^{2}$, chi-square test; FE, Fisher exact; $t$, Student's $t$ test; $U$, Mann-Whitney test; $p, p$ value for comparing between the two studied groups; ${ }^{t} p$, $\mathrm{p}$ value for paired $t$ test for comparing between two studied periods in each group and total; ${ }^{z} p, p$ value for Wilcoxon signed-rank test for comparing between two studied periods in each group and total; NSE, neuron-specific enolase; NIHSS, National Institutes of Health Stroke Scale *Statistically significant at $p \leq 0.05$

mean total NIHSS score at 28 days was significantly higher in the death group $(25.7 \pm 3.2)$ than in the nodeath group $(13.7 \pm 3.8)(P<0.001)$ (Table 4).

The neuron-specific enolase mean serum level at presentation was significantly elevated in the death group $(34.5 \pm 6.2)$ than in the no-death group $(23.1 \pm 8.1)(P=$ $0.007)$. Also, the neuron-specific enolase mean serum level after $48 \mathrm{~h}$ was significantly elevated in the death group $(33.0 \pm 5.5)$ than in the no-death group $(22.3 \pm$ 7.7) $(P=0.007)($ Table 4$)$.

Table 5 Correlation between the serum level neuron-specific enolase (NSE) and the clinical severity of stroke (NIHSS) among the patients $(n=37)$

\begin{tabular}{lll}
\hline NIHSS & \multicolumn{2}{l}{ NSE at presentation } \\
\cline { 2 - 3 } & $\boldsymbol{r}_{\mathrm{s}}$ & $\boldsymbol{p}$ \\
\hline Total & 0.737 & $0.000^{*}$ \\
No death & 0.685 & $0.03^{*}$ \\
Death & 0.853 & $0.000^{*}$ \\
\hline
\end{tabular}

$r_{s}$, Spearman coefficient; NSE, neuron-specific enolase; NIHSS, National Institutes of Health Stroke Scale

*Statistically significant at $p \leq 0.05$
There was a statistically significant positive correlation between NSE serum level and clinical severity of stroke (NIHSS) among the patients at presentation $(r=0.737, p$ $=0.000)$, and this positive correlation was higher in the death group than in the no-death group $(r=0.853, p=$ 0.000 , and $r=0.685, p=0.03$, respectively) (Table 5).

The NSE serum level cutoff value to anticipate mortality at presentation was $>33.45$ with sensitivity $66.67 \%$ and specificity $96.77 \%$. The cutoff value of NSE serum level to predict mortality at $48 \mathrm{~h}$ was $>31.04$ with sensitivity $66.67 \%$ and specificity $93.55 \%$ (Table 6) (Fig. 1). The NIHSS cutoff value to anticipate mortality at presentation was $>19$ with a sensitivity $100 \%$ and a specificity 90.32\% (Table 6) (Fig. 2).

\section{Discussion}

The current study assesses the role of NSE as a biomarker to evaluate injury of brain parenchyma in ischemic stroke therefore tracking the progression of the illness. It is necessary to have brain markers highly sensitive to be detected in blood rather than the CSF. Since samples of blood can be taken routinely and independently of elevated intracranial tension. 
Table 6 Agreement (sensitivity, specificity) for serum level of neuron-specific enolase (NSE) and clinical severity of stroke (NIHS S)predict mortality $(n=6)$

\begin{tabular}{lllllllll}
\hline NSE & AUC & $\boldsymbol{p}$ & $\mathbf{9 5 \%}$ C.I & Cutoff $^{\text {a }}$ & Sensitivity & Specificity & PPV & NPV \\
\hline NSE at presentation & 0.836 & $0.010^{*}$ & $0.642-1.030$ & $>33.45$ & 66.67 & 96.77 & 80.0 & 93.7 \\
NSE at 48 $\mathrm{h}$ & 0.855 & $0.007^{*}$ & $0.690-1.019$ & $>31.04$ & 66.67 & 93.55 & 66.7 & 93.5 \\
NIHSS at presentation & 0.978 & $<0.001^{*}$ & $0.938-1.019$ & $>19$ & 100.0 & 90.32 & 66.7 & 100.0
\end{tabular}

$A U C$, area under a curve; $p$ value, probability value; $C l$, confidence intervals; NPV, negative predictive value; $P P V$, positive predictive value; $N S E$, neuron-specific enolase; NIHSS, National Institutes of Health Stroke Scale

*Statistically significant at $p \leq 0.05$

${ }^{a}$ Cutoff was chosen according to Youden index

In our study, we found that serum NSE levels in stroke patients in the death group were detected at presentation within $6 \mathrm{hrs}$. and 48hrs. after admission were significantly elevated than the no death group. This was consistent with Bharosay and colleagues [12] who reported that the mean NSE serum level was significantly elevated in stroke patients $(\mathrm{P}<0.001)$ relative to controls.

As NSE present in the cytoplasm of neuronal cells, its presence in the serum at significant high levels indicates neuronal damage according to Bharosay and colleagues [12] who reported that endothelial cell death disrupts the blood brain barrier during stroke, and the released cytoplasmic contents from damaged brain tissues disseminate through it. On the other hand, Fassbender and colleagues [13], Casmiro and colleagues [14], and Anand and Stead [15], in their researchs, reported that serum NSE levels are less sensitive, scarcely exceeding the reference value, and a larger degree of damage is needed to yield a reliably detectable differences. This can be demonstrated by the timing of the sample's withdrawal; also, the use of different kits.

In our study, stroke severity was assessed using NIHSS, and It was found a strong positive correlation existed between NIHSS scores and serum NSE levels at presentation. this positive correlation was higher in the death group than in the no death group, Patients with higher NIHSS were found to have significantly higher

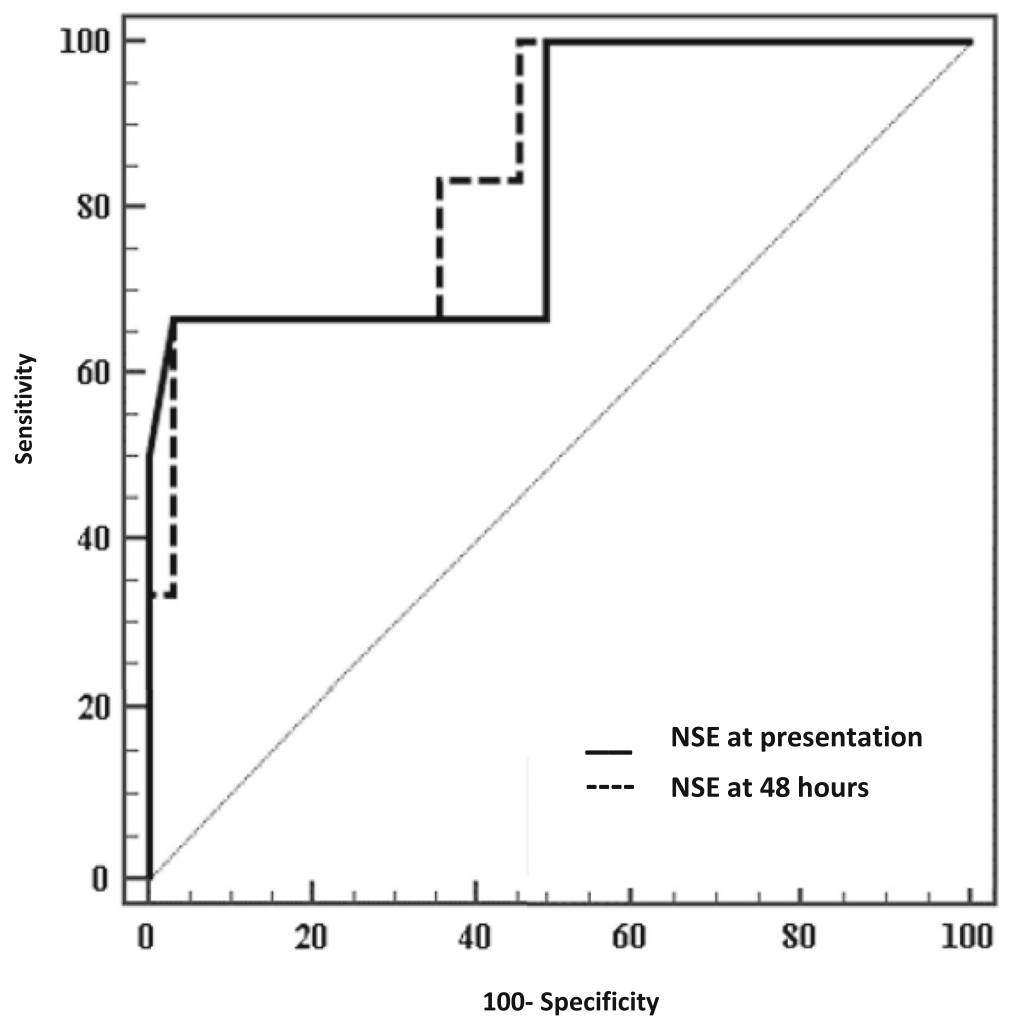

Fig. 1 ROC curve for neuron-specific enolase (NSE) level predict mortality $(n=6)$. The NSE serum level cutoff value to anticipate mortality at presentation was $>33.45$ with sensitivity $66.67 \%$ and specificity $96.77 \%$. The cutoff value of NSE serum level to predict mortality at $48 \mathrm{~h}$ was > 31.04 with sensitivity $66.67 \%$ and specificity $93.55 \%$ 


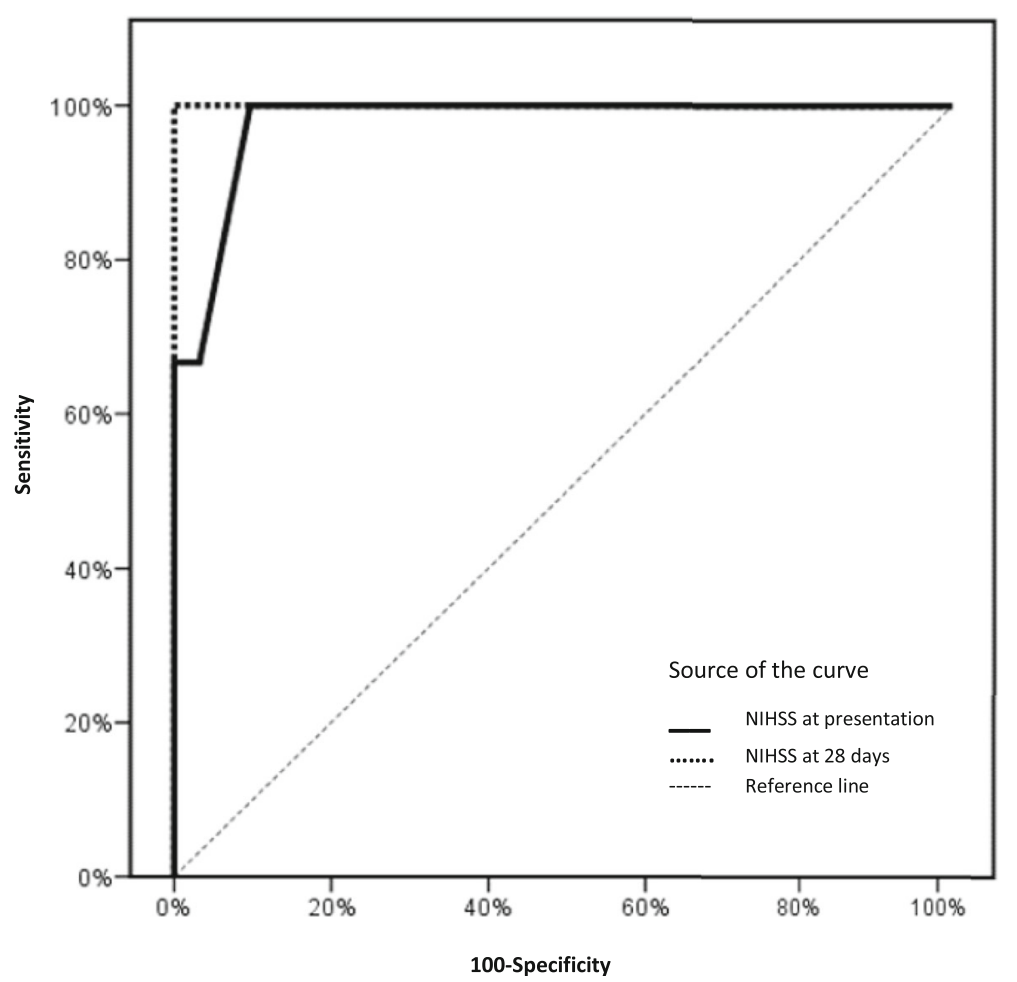

Fig. 2 ROC curve for NIHSS to predict mortality $(n=6)$. The NIHSS cutoff value to anticipate mortality at presentation was $>19$ with a sensitivity $100 \%$ and a specificity $90.32 \%$

NSE levels compared with those with lower NIHSS. Such findings are consistent with the study conducted by Brea and colleagues [16] who stated that the peak serum NSE concentration associated with stroke severity was at admission assessed by the NIHSS $(\mathrm{P}=0.0001)$. Jauch and colleagues [17] also reported that higher 24 hrs. maximum NSE concentrations were associated with higher baseline NIHSS scores $(\mathrm{P}=0.032)$.

Ergün and colleagues [18], Wunderlich and colleagues [19], and Oh and colleagues [20] also confirmed that higher serum NSE levels associated with worse clinical outcomes. Wunderlich and colleagues [19] noted that serum NSE levels were expected to rise as infarction progressed and NSE released from brain tissue $(\mathrm{P}<$ $0.001)$. As the recovery depends on the stroke initial severity, at admission time, patients with higher serum NSE levels were more subjected to poor neurological outcome $(\mathrm{P}<0.001)$, the NSE serum concentrations were highly correlated with the degree of NIHSS-assessed neurological severity. The early serum NSE levels associated with the NIHSS score at admission $(\mathrm{P}=0.002)$ Additionally, according to González and colleagues [21], serum NSE levels were correlated to the level of recovery and functional outcome neurological state at 60 days. This was consistent with Singh and colleagues [22] and Pandey and colleagues [23] who stated that in their studies, NSE is associated with the extent of neurological dysfunction $(\mathrm{P}=0.001)$ as we found in this study $(\mathrm{P}<$ $0.001)$.

The NIHSS total score is more dependable in predicting the outcome of stroke, which is specifically more sensitive and specific than both measurements. This study shows that the NIHSS scoring system is more specific and sensitive compared to the NSE serum levels either on presentation or after $48 \mathrm{hrs}$. as a predictor of the outcome of stroke. So in patients with acute ischemic stroke, NSE is a strong biochemical predictor of functional outcome, and our research indicates that although the exact size of the infarction was not reliably determined, the initial NSE levels correlated properly with the degree of stroke severity.

The limitations of this study were the existence of patients acutely in ER within the first 6hours, no available biochemical marker valid for the prognosis of stroke to compare with and the cost of the NSE kits and its availability at ER.

\section{Conclusion}

Neuron-specific enolase (NSE) can be applied as single independent marker for prediction of mortality and short-term morbidity in ischemic stroke patients. However, to develop those observations more firmly, larger studies with serial estimation of NSE are required. 


\section{Abbreviations}

EIA: Enzyme Immunometric Assay; ER: Emergency Room; NSE: Neuronspecific enolase; NIHSS: National Institutes of Health Stroke Scale; $\mu \mathrm{g} /$ L: Micrograms per liter

\section{Acknowledgements \\ "Not applicable"}

\section{Authors' contributions}

SM participated by acquisition of data and performed the statistical analysis. AR carried out the design of the study and the analysis and interpretation of data and helped to draft the manuscript. AN participated in the sequence alignment, interpretation of data, and drafting of the manuscript. AR carried out the study conception and design and participated in its design. EA carried out the study conception and design, participated in its design and coordination, and drafted the manuscript. All authors read and approved the final manuscript.

\section{Funding}

The Authors were responsible for the cost of this study including the design of the study and collection, analysis, and interpretation of data and in writing the manuscript and no funding.

\section{Availability of data and materials}

The data can be publicly available at the Faculty of Medicine, Suez Canal University.

\section{Ethics approval and consent to participate}

The study was approved by the Ethics committee of Suez Canal Faculty of Medicine on September 9, 2017.

Committee Number: 3164

An informed written consent was taken from all the participants in the study.

\section{Consent for publication}

Participants signed an informed consent for publication

\section{Competing interests}

"The authors declare that they have no competing interests (financial or non-financial)."

\section{Author details}

${ }^{1}$ Department of Emergency Medicine, Suez Canal University, Ismailia, Egypt. ${ }^{2}$ Department of Neurology, Faculty of Medicine, Suez Canal University, Ismailia, Egypt.

Received: 13 March 2020 Accepted: 4 January 2021

\section{Published online: 17 February 2021}

\section{References}

1. Lozano R, Naghavi M, Foreman K, Lim S, Shibuya K, Aboyans V, et al. Global and regional mortality from 235 causes of death for 20 age groups in 1990 and 2010: a systematic analysis for the Global Burden of Disease Study 2010. Lancet. 2012:380(9859):2095-128.

2. Krishnamurthi RV, Feigin VL, Forouzanfar MH, Mensah GA, Connor M, Bennett DA, et al. Global and regional burden of first-ever ischaemic and haemorrhagic stroke during 1990-2010: findings from the Global Burden of Disease Study 2010. Lancet Glob Health. 2013:1(5):e259-81.

3. Feigin VL, Forouzanfar MH, Krishnamurthi R, Mensah GA, Connor M, Bennett DA, et al. Global and regional burden of stroke during 1990-2010: findings from the Global Burden of Disease Study 2010. Lancet. 2014;383(9913):24555.

4. Abd-Allah F, Moustafa RR. Burden of stroke in Egypt: current status and opportunities. Int J Stroke. 2014;9(8):1105-8.

5. Oberg K, Jelic S. ESMO Guidelines Working Group: Neuroendocrine gastroenteropancreatic tumors: ESMO clinical recommendation for diagnosis, treatment, and follow-up. Ann Oncol. 2009:20:150-3.

6. Horn M, Schlote W. Delayed neuronal death and delayed neuronal recovery in the human brain following global ischemia. Acta Neuropathol. 1992;85(1): 79-87.
7. Takei N, Kondo J, Nagaike K, Ohsawa K, Kato K, Kohsaka S. Neuronal survival factor from bovine brain is identical to neuron-specific enolase. J Neurochem. 1991;57(4):1178-84.

8. Hill MD, Jackowski G, Bayer N, Lawrence M, Jaeschke R. Biochemical markers in acute ischemic stroke. CMAJ. 2000;162(8):1139-40.

9. Lamberts SW, Hofland L, Nobels FR. Neuroendocrine tumor markers. Front Neuroendocrinol. 2001;22(4):309-39.

10. Appelros P, Terént A. Characteristics of the National Institute of Health Stroke Scale: results from a population-based stroke cohort at baseline and after one year. Cerebrovasc Dis. 2004;17(1):21-7.

11. Bamford J, Sandercock P, Dennis M, Warlow C, Burn J. Classification and natural history of clinically identifiable subtypes of cerebral infarction. Lancet. 1991:337(8756):1521-6.

12. Bharosay A, Bharosay W, Varma M, Saxena K, Sodani A, Saxena R. Correlation of brain biomarker neuron specific enolase (NSE) with degree of disability and neurological worsening in cerebrovascular stroke. Indian J Clin Biochem. 2012;27(2):186-90.

13. Fassbender K, Schmidt R, Schreiner A, Fatar M, Mühlhauser F, Daffertshofer $M$, et al. Leakage of brain-originated proteins in peripheral blood: temporal profile and diagnostic value in early ischemic stroke. J Neurol Sci. 1997; 148(1):101-5.

14. Casmiro M, Maitan S, De Pasquale F, Cova V, Scarpa E, Vignatelli L, et al. Cerebrospinal fluid and serum neuron-specific enolase concentrations in a normal population. Eur J Neurol. 2005;12(5):369-74.

15. Anand N, Stead LG. Neuron-specific enolase as a marker for acute ischemic stroke: a systematic review. Cerebrovasc Dis. 2005;20(4):213-9.

16. Brea D, Sobrino T, Blanco M, Cristobo I, Rodríguez-González R, RodríguezYañez $M$, et al. Temporal profile and clinical significance of serum neuronspecific enolase and S100 in ischemic and hemorrhagic stroke. Clin Chem Lab Med. 2009;47(12):1513-8.

17. Jauch EC, Lindsell C, Broderick J, Fagan SC, Tilley BC, Levine SR. Association of serial biochemical markers with acute ischemic stroke: The National nstitute of Neurological Disorders and Stroke recombinant tissue plasminogen activator Stroke Study. Stroke. 2006;37(10):2508-13.

18. Ergün R, Bostanci U, Akdemir G, Beșkonakli E, Kaptanoğlu E, Gürsoy F, et al. Prognostic value of serum neuron-specific enolase levels after head injury. Neurol Res. 1998:20(5):418-20.

19. Wunderlich MT, Lins H, Skalej M, Wallesch CW, Goertler M. Neuron-specific enolase and tau protein as neurobiochemical markers of neuronal damage are related to early clinical course and long-term outcome in acute ischemic stroke. Clin Neurol Neurosurg. 2006;108(6):558-63.

20. Oh SH, Lee JG, Na SJ, Park JH, Choi YC, Kim WJ. Prediction of early clinical severity and extent of neuronal damage in anterior-circulation infarction using the initial serum neuron-specific enolase level. Arch Neurol. 2003; 60(1):37-41

21. González-García S, González-Quevedo A, Fernández-Concepción O, PeñaSánchez M, Menéndez-Saínz C, Hernández-Díaz Z, et al. Short-term prognostic value of serum neuron specific enolase and S100B in acute stroke patients. Clin Biochem. 2012;45(16-17):1302-7.

22. Singh HV, Pandey A, Shrivastava AK, Raizada A, Singh SK, Singh N Prognostic value of neuron specific enolase and IL-10 in ischemic stroke and its correlation with degree of neurological deficit. Clin Chim Acta. 2013; 419:136-8.

23. Pandey A, Shrivastava AK, Saxena K. Neuron specific enolase and c-reactive protein levels in stroke and its subtypes: correlation with degree of disability. Neurochem Res. 2014;39(8):1426-32

\section{Publisher's Note}

Springer Nature remains neutral with regard to jurisdictional claims in published maps and institutional affiliations. 